\title{
Parcerias entre a Escola e a Comunidade em Portugal: Uma Análise a partir da Avaliação Externa das Escolas*
}

Carlinda Leite ${ }^{1}$

Preciosa Fernandes ${ }^{1}$

Ana Mouraz

Marta Sampaio ${ }^{1}$

${ }^{1}$ Universidade do Porto, Porto, Portugal.

E-mail: carlinda@fpce.up.pt

\section{INTRODUÇÃO}

\begin{abstract}
À
semelhança de outros países, em Portugal, o local e, nele, a escola, ganharam um novo protagonismo com as políticas de descentralização educacional iniciadas no final da década de 1980 do século XX. Este movimento, que corresponde ao que tem sido designado como "territorialização da educação" (Leite, 2005), aposta na articulação da instituição escolar com outras instituições locais e na atribuição de responsabilidades coletivas para com os diversos elementos das comunidades (Andrade, 2003; Correia, 2004). Por isso, a territorialização tem sido apontada para promover uma educação de melhor qualidade para todos. Neste sentido, ela pressupõe a existência de autonomia nas decisões educacionais que viabilizem a inserção no currículo escolar de saberes e práticas de contextos familiares (Cavaliere, 2002).

É também tendo estas ideias por referência que o estabelecimento de parcerias entre a escola e a comunidade passou a constituir uma nova prática educacional e social e o território passou a ser entendido como um espaço para empreender políticas públicas diferenciadas (Delgado e Leite, 2011). Estas políticas educativas orientam-se segundo um paradigma organizativo que responsabiliza os diversos agentes locais
\end{abstract}

\footnotetext{
* Esta pesquisa é financiada pelo Fundo Europeu de Desenvolvimento Regional (Feder), através do Programa Operacional Factores de Competitividade (Compete) e pela Fundação para a Ciência e a Tecnologia (FCT) no âmbito do programa Ciência 2007.
}

DADOS - Revista de Ciências Sociais, Rio de Janeiro, vol. 58, no-3, 2015, pp. 825 a 855. 
pela resolução dos vários problemas que se colocam à instituição escolar, processo que se tornou uma obrigação, mais do que um direito à participação (Dias, 2003).

Foi no quadro desta situação que o movimento de accountability (Afonso, 2009; Fullan, Rincon-Gallardo, Hargreaves, 2015), entendido no sentido não apenas da prestação de contas, mas também de responsabilização e controle pelas ações educativas desenvolvidas, foi ganhando terreno. No âmbito deste movimento, no contexto português, foi emergindo a política da avaliação de escolas (Clímaco, 2005) e nela o modo como estas se inserem nos territórios locais e como constroem parcerias com as diversas instituições e agentes dessas comunidades.

Relacionado com estas ideias, medidas de avaliação das instituições escolares foram também ocupando espaço nas políticas de educação. Embora em Portugal a avaliação das escolas de ensino fundamental e médio estivesse prevista desde a publicação da primeira Lei de Bases do Sistema Educativo (Lei no 46/1986), só em 2002 (Lei no 31 / 2002) foi definida a obrigatoriedade destas escolas realizarem processos de autoavaliação (art. 6). No seguimento deste processo, no ano de 2006 foi iniciada a avaliação externa das escolas (AEE) públicas, constituindo o que foi designado como 1 o ciclo avaliativo.

A medida política que definiu este procedimento estabeleceu que até 2011 seriam sujeitas a uma AEE todas as escolas dos ensinos fundamental e médio de modo a: 1) promover a melhoria, a eficiência e a eficácia do sistema; (2) responsabilizar as escolas pela prestação de contas; (3) apoiar as tomadas de decisão. A responsabilidade desta AEE foi atribuída à Inspeção Geral da Educação (IGE), que em 2011 passou a ser designada por Inspeção Geral da Educação e da Ciência (IGEC).

O 1 ciclo de AEE decorreu de 2006 a 2011, período em que foram avaliadas todas as escolas, seguindo-se um 20 ciclo, atualmente em vigor, que se supõe terminado em 2015. Esta avaliação externa segue um referencial que estrutura o processo de coleta de dados e apoia a elaboração de um relatório, que justifica as classificações atribuídas. O relatório que dá conta da $\mathrm{AEE}$ é devolvido à escola e posteriormente colocado na plataforma da IGEC para conhecimento público (IGEC, 2011). O referencial usado nesta AEE teve por base o modelo escocês How Good is our School (Clark, 2000) e abrange aspectos relacionados com os resultados dos alunos, a prestação do serviço educativo, as questões da organização, gestão e liderança escolares e as dinâmicas 
de autoavaliação. No 1ำ ciclo de AEE este referencial estruturou-se em torno de cinco domínios que, no 2 e ciclo, sofreram reajustes, passando a focar: (1) resultados; (2) prestação do serviço educativo; (3) liderança e gestão. As classificações atribuídas a cada um dos domínios variam entre o Insuficiente, Suficiente, Bom e Muito Bom. No 2o ciclo, com as alterações sofridas no referencial, à escala de classificações foi acrescentado o Excelente.

As relações de parceria entre a escola e a comunidade local, aspecto em foco neste artigo, são alvo de avaliação no domínio da "prestação do serviço educativo". É a análise dos dados recolhidos dos relatórios de AEE relativos a este domínio que permite responder às seguintes questões: (1) As parcerias são valorizadas pelas escolas e pelas comunidades? (2) As parcerias estabelecidas pelas escolas do ensino público português configuram práticas de territorialização da educação? (3) Se sim, quais são as áreas mais valorizadas? (4) Que efeitos geram as parcerias ao nível da oferta educativa, da inovação curricular e do estabelecimento de protocolos nacionais e internacionais?

Tendo por referência este questionamento, o artigo tem como objetivos: produzir conhecimento sobre o valor que está a ser atribuído às parcerias entre a escola e as comunidades locais no processo de AEE; caraterizar os efeitos gerados na institucionalização de parcerias e que promovam uma corresponsabilização social e coletiva pela educação e formação de crianças e jovens das comunidades em que se inserem as escolas.

Para cumprir estes objetivos, a análise dos relatórios produzidos na AEE focou-se nas parcerias entre as escolas e as comunidades, nas áreas que são privilegiadas e nas relações entre essas áreas e os efeitos gerados. Nesta última, isto é, nas relações e efeitos, a análise centrou-se no alargamento da oferta educativa, na inovação curricular e no desenvolvimento de projetos nacionais e/ou internacionais.

\section{POLÍTICAS DE TERRITORIALIZAÇÃO DA AÇÃO EDUCATIVA E DE VALORIZAÇÃO DE PARCERIAS LOCAIS}

Justificada na intenção de atender às especificidades dos contextos locais, isto é, dos vários territórios, as políticas de territorialização preconizaram a ideia de descentralização e de uma escola aberta ao meio. Estas políticas implicaram, pois, a transferência de poderes para os territórios locais e abriram caminho para que as escolas e o local sejam reco- 
nhecidos como espaços de decisão educacional. Por outro lado, essa transferência de poderes e de responsabilidades requereu, entre outros aspectos, o estabelecimento de parcerias locais e interinstitucionais capazes de fortalecer uma participação coletiva na educação. Partiu-se da ideia de que esta participação na vida das escolas pode ser potenciadora de melhoria educacional. No entanto, para isso, é necessário que se oriente por uma ação concertada e coletiva. Como adverte Cavaliere (2007:1032), "a participação de organizações da sociedade civil e de outras instâncias da administração pública é desejável e pode ser enriquecedora, desde que isso não signifique pulverização das ações e sim o fortalecimento da instituição escolar".

O que aconteceu em Portugal ocorreu igualmente em outros países que adotaram políticas educacionais de responsabilização das instituições locais para colmatar falhas do Estado. Reconheceu-se que problemas sociais que afetam algumas comunidades têm efeitos na formação e na aprendizagem dos alunos, dificultando, por isso, a concretização dos princípios de equidade e justiça social (Santomé, 2013). Esta medida política de transferência de responsabilidades para os locais foi acompanhada pela introdução de políticas de avaliação que permitam conhecer o desempenho do sistema educativo e dos diferentes estabelecimentos de ensino e a possibilidade de compará-los.

É neste cenário de descentralização e territorialização da educação que o Estado assume um papel regulador (Dale, 1989; Afonso e Costa, 2011). Ou seja, a acompanhar o discurso político que aponta para a autonomia das escolas, têm sido instituídos mecanismos que permitem ao Estado exercer o seu controle (Afonso, 2009). A avaliação das escolas transforma-se, então, em ferramenta de pilotagem (Rochex, 2011), sendo-lhe também atribuídas funções de transformação das políticas educativas, das práticas profissionais e dos currículos. Nesta sequência, estas políticas públicas iniciaram processos legislativos e organizativos que fazem conviver a avaliação interna das escolas e a autoavaliação com a avaliação externa (Leite, Rodrigues e Fernandes, 2006), fazendo emergir "o advento de novos modos de regulação" (Rochex, 2011:3). Estas novas formas de regulação deram lugar a discursos fundados na autonomia, na diversificação da oferta escolar e na inovação. Como foi afirmado por Estaço (2001:13), assistiu-se a "uma rotação no modo de pensar a educação, os sistemas educativos e a mudança que radica num novo olhar sobre as escolas (e o contexto local em que estão inseridas), fazendo incidir a necessidade e a oportunidade de aí cen- 
trar as medidas de inovação e de mudança". Nas palavras desta autora, o discurso da territorialização ficou na ordem do dia, devendo a escola traçar a sua identidade e construir-se em concordância com o meio em que se insere, procurando soluções locais para a resolução dos seus problemas. Em síntese, e como temos argumentado, tratou-se de devolver poderes ao local concretizando princípios de descentralização, de participação e de autonomia (Ferreira, 2005) através de práticas de responsabilização decorrentes da reconfiguração da função reguladora do Estado (Afonso e Costa, 2011).

Relativamente às escolas, estas práticas de descentralização e de responsabilização implicaram a adoção de procedimentos que correspondessem aos princípios da autonomia escolar e à construção de entendimentos locais que dependem da constelação de atores existentes no contexto (Formosinho, 2005; Alves, 2010; Burgos, 2012). Para isso, como já foi ressaltado, é importante ter presente que a revalorização do local pressupõe a compreensão dos referenciais que suportam o discurso estatal: ação local, autonomia, territorialização, participação, responsabilidade, formação e projeto (Correia e Caramelo, 2008).

Esta ideia tem estado também presente nas políticas públicas europeias que fazem um apelo à importância da dimensão local, com particular incidência na procura de respostas para problemas sociais e econômicos (Rodrigues e Stoer, 1994). A concepção de escola fechada em si mesma, sem ligação com o meio que a circunda, desapareceu do discurso político, dando lugar à ideia de escola como um espaço de intervenção aberto ao exterior (OECD, 2012). No quadro deste discurso político, o território educativo tem vindo a ser assumido como um operador simbólico de grande força, gerador de múltiplos sentidos que aproximam o território e a escola (Dias, 2003; Tura e Silva, 2010; Batista, 2012).

Todavia, Van Zanten (2010) e Raveaud e Van Zanten (2007), referindo-se à interação das escolas com as famílias, consideram que essa interação não se faz sempre no sentido de potenciar a maior diversificação e inclusão social. Muitas vezes, as estratégias seguidas por certas famílias influenciam os modos de agir das escolas, transformando-as em lugares de estratificação social. Apesar disso, na linha de pensamento veiculada por Santos (1994), é o sentido comunitário da ação que permite a politização dos contextos e potencia a emergência de uma nova cidadania. Em consonância com esta ideia, e referindo-se às 
Zones d'Éducation Prioritaire (ZEP), Gérard Chauveau, na década de 1980, afirmava que no campo educativo é necessário:

pensar em termos de ação educativa global e não limitar a ação aos processos de ensino; integrar o ensino no seu contexto social e cultural; iniciar uma pedagogia aberta à vida da cidade ou ao setor rural, aberta a uma série de participantes; criar um espaço educativo com a participação efetiva dos diversos componentes da vida educativa (1982:12).

Em sintonia com esta ideia, os Territórios Educativos de Intervenção Prioritária (TEIP), criados em Portugal no ano de 1996, surgiram como medida de política pública de resolução de problemas relacionados com a desigualdade social e com o abandono e o insucesso escolar (Barbieri, 2003; Leite, Fernandes e Silva, 2013). Isto é, esta medida reconhece no local e nas parcerias interinstitucionais mais-valias para diagnosticar problemas e neles intervir coletivamente. Desta forma, estas políticas têm como meta que a educação escolar e o currículo vivido contribuam para uma sociedade mais justa (Connell, 1997; Apple e Beane, 2000; Beane, 2000; Doll Jr., 2004; Santomé, 2013).

O que estamos aqui a realçar é que "o renovado interesse pelo local, no último quartel do século XX, está associado à crescente complexidade dos problemas sociais e da sua também crescente visibilidade social, política, científica e mediática" (Ferreira, 2005:84). Ao mesmo tempo, reconhecemos que a valorização de parcerias no discurso legal "está relacionada com a própria incapacidade dos poderes públicos centrais para encontrarem soluções para os problemas do desemprego, da pobreza, da injustiça social, que emergiram ou se agravaram nesse período" (idem).

Em consonância ainda com este autor, e apesar de nos guiar a crença dos benefícios que podem decorrer das parcerias da escola com instituições e agentes das comunidades locais, há que admitir que o local não é detentor de todas as soluções para os problemas com os quais as escolas se defrontam. Ou seja, com Ferreira (2005:101) sustentamos que é preciso encarar "(...) o local como um universo compósito, perspectivando-o como palco de contraste, controvérsia e contradições". E, nesse raciocínio, estabelecer parcerias que se constituam como redes que libertam e não como redes que aprisionam (Ferreira, 2012).

Tendo por referência estas ideias, consideramos, contudo, que as parcerias podem constituir uma prática social inovadora (Estaço, 2001) e uma via através da qual é possível estabelecer uma maior e melhor co- 
municação escola-comunidade promotora de sinergias positivas e com reciprocidades significativas.

Em síntese, do discurso de uma escola isolada das situações que ocorrem na comunidade foi-se evoluindo para um discurso de uma escola que interage com ela. Nesta concepção de escola são mobilizados os recursos locais e partilhada, com as famílias e outros agentes da comunidade, a responsabilidade por configurar e concretizar um projeto educativo contextualizado (Leite, 2003) e com sentido para as populações que o vivem. É também no quadro desta interação que começa a ser apagada dos discursos educativos e das ações desenvolvidas a ideia de uma escola que não tem em conta as especificidades das populações a quem ela se destina. Ou seja, é fortalecida a visão de uma escola que se amplia às instituições da comunidade, dando sentido à "cidade educativa" (Faure, 1981) hoje presente no movimento das "cidades educadoras" (Vilar Caballo, 2001).

\section{A AVALIAÇÃO EXTERNA DAS ESCOLAS EM PORTUGAL}

A avaliação externa das escolas em Portugal tem sido justificada pelo objetivo de contribuir para a melhoria da qualidade das aprendizagens dos alunos e promover o aperfeiçoamento contínuo das escolas/agrupamento de escolas ${ }^{1}$. Como é afirmado pela IGEC, tem sido

(...) valorizado o desenvolvimento de práticas de regulação que contribuem para o desenvolvimento de procedimentos sistémicos e institucionais de avaliação externa e que promovem a prestação de contas e a melhoria da qualidade do ensino e das aprendizagens (IGEC, 2011:16).

Como se referiu na introdução deste artigo, o referencial seguido pela

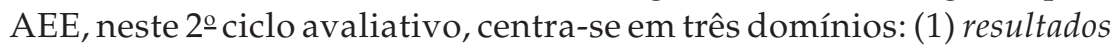
(acadêmicos e sociais e o reconhecimento da escola na comunidade); (2) prestação do serviço educativo (gestão do currículo, práticas de ensino, práticas de monitorização e avaliação e práticas de inclusão e equidade); e (3) lideranças e gestão escolar (visão da escola/agrupamento de escolas, estratégia e planeamento, gestão dos recursos, desenvolvimento pessoal e organizacional, autoavaliação e melhoria) ${ }^{2}$. É no domínio da prestação de serviço educativo, em foco nesta investigação, que estão incluídas as vivências curriculares que contribuem para a formação dos alunos e para as quais concorrem também as interações e as parcerias desenvolvidas entre as escolas e as comunidades envolventes. Por outro lado, este referencial de avaliação insere-se numa orien- 
tação internacional (Santiago et al., 2012) e tem de ser no seu quadro interpretado.

No caso português, o modelo de AEE é apresentado como um instrumento formativo de avaliação da qualidade escolar (Leite e Pacheco, 2010) e é encarado como um processo de inovação no qual os relatórios de avaliação produzidos podem constituir instrumentos de apoio à (re)construção social das escolas (Veloso, Abrantes e Craveiro, 2011) e de regulação da melhoria educacional. Esta direção das políticas de avaliação educacional está, como sugeriram Davies, Newcomer e Soydan (2007), diretamente relacionada com a verificação de resultados e de efeitos. Ou seja, à AEE está associada a ideia de accountability (Afonso, 2009; Fullan, Rincon-Gallardo e Hargreaves, 2015) que implica a prestação de contas mas também a responsabilização pela melhoria.

\section{METODOLOGIA}

Para a realização deste estudo foram analisados relatórios de 52 agrupamentos de escolas, que correspondem a 20,8\% dos agrupamentos de escolas do norte e do centro de Portugal avaliados em 2012/2013. A escolha dos relatórios destas duas zonas geográficas justifica-se por corresponderem a $60 \%$ das escolas/agrupamentos de escolas existentes em Portugal (num total de 144 escolas / agrupamentos avaliados, 87 dizem respeito ao norte e ao centro do país) e por corresponderem a zonas marcadas por problemas sociais (Sarmento, 2002). Desses agrupamentos, foram estudados os relatórios produzidos no 1 - ciclo de avaliação (ocorrido entre 2006 e 2011) e os do 2 ㅇclo (iniciado em 2011), perfazendo o total de 104 documentos analisados.

A seleção desses 52 agrupamentos de escolas foi feita a partir de dois critérios: escolas que, do 1으 para o 2 을 ciclo de avaliação, subiram na classificação que lhes foi atribuída na AEE e escolas que, no $2 \underline{0}$ ciclo de AEE, desceram ou mantiveram as classificações obtidas no 1o ciclo. Assim, depois de ter sido realizado o levantamento das classificações de todos os agrupamentos de escolas no plano nacional, foram escolhidos aqueles que obedeciam a estes critérios. Por outro lado, foi considerado o número total de agrupamentos de escolas existentes na zona Norte e no Centro de Portugal de modo a selecionar-se uma porcentagem próxima dos $20 \%$ do total. Este procedimento levou a selecionar 34 relatórios da zona Norte (17 que subiram nas classificações e 17 que 
desceram ou se mantiveram) e 18 do Centro ( 9 que subiram e 9 que desceram ou se mantiveram nas classificações obtidas no 1ํㅜ ciclo de AEE).

A opção por este instrumento de coleta de dados assentou em dois pressupostos: por um lado, os relatórios produzidos pelas equipes de avaliação externa traduzem um retrato relativamente fidedigno das instituições escolares; por outro, estes relatórios, nos discursos avaliativos devolvidos às escolas, influenciam-nas na forma como organizam os seus projetos educativos e na atenção que dão às várias dimensões educacionais. Por isso, foi fundamental comparar, para cada agrupamento de escolas avaliado, os relatórios produzidos no 1o e no 2 ํㅜciclo de AEE. Nessa comparação, a análise foi concentrada nas questões de pesquisa enunciadas a que se acrescentou o desejo de saber se a existência de parcerias e o valor que lhes é atribuído está relacionado com as classificações obtidas na AEE.

A pesquisa seguiu a técnica da análise de conteúdo (Bardin, 2011; Krippendorf, 2003) com apoio do programa NVivo (v. 10) e focou, como já foi referido, especificamente o domínio Prestação de Serviço Educativo. Para a apresentação dos dados, os relatórios foram contabilizados como fontes unitárias. Para além disso, considerou-se o número de referências / unidades de sentido neles constantes. Definiu-se como unidade de sentido a frase, ainda que em algumas circunstâncias essa unidade tenha sido alargada de forma a incluir outros elementos complementares da ideia que a frase veiculava.

Num primeiro momento, foram contabilizados os relatórios e as referências relativas às parcerias escola-comunidade. Seguindo este procedimento, a estrutura analítica, que também sequencia a apresentação dos resultados, centrou-se em duas dimensões: áreas das parcerias e seus efeitos. A primeira dimensão - áreas das parcerias - foi estruturada num conjunto de categorias definidas de acordo com as áreas a que se reportavam as parcerias referenciadas nos relatórios, a saber: artes; conhecimento científico; desporto; intervenção familiar; saúde; ação social; equipamentos/serviços educativos; formação/desenvolvimento profissional; apoio psicológico. A categoria artes inclui referências que dizem respeito a ações de promoção e de sensibilização do ensino artístico e a projetos que as escolas realizam neste âmbito; as referências a parcerias na área do conhecimento científico estão relacionadas, fundamentalmente, com a promoção do ensino experimental; a área do desporto é referenciada sobretudo no que respeita a instalações da comunidade e que consti- 
tuem um recurso para as escolas; as referências à área de intervenção familiar relacionam-se com parcerias estabelecidas entre a escola e as famílias, na sua relação com a atividade do gabinete do apoio ao aluno; na categoria saúde estão incluídas referências relativas a parcerias existentes entre as escolas e as instituições locais de saúde na promoção de ações para a comunidade escolar; as referências à ação social relacionam-se com parcerias entre as escolas e as instituições locais respondendo de forma articulada às necessidades de todos os alunos; a categoria equipamentos/serviços educativos inclui referências a parcerias que apoiam as escolas na manutenção do equipamento escolar e na melhoria dos seus serviços; as referências à formação/desenvolvimento profissional focam-se nas parcerias criadas pelas escolas para promover o desenvolvimento profissional dos professores (por exemplo, parcerias com centros de formação de professores); as referências à categoria apoio psicológico referem-se aos serviços de psicologia e ao seu papel no acompanhamento dos alunos.

A segunda dimensão - efeitos das parcerias - foi organizada nas seguintes categorias: alargamento da oferta formativa; inovação curricular e adesão a projetos nacionais e/ou internacionais. A categoria alargamento da oferta formativa inclui referências/unidades de sentido ligadas à adesão, por parte das diferentes escolas, a novas áreas de educação e formação com o estabelecimento de parcerias; a categoria inovação curricular relaciona-se com diversificação de experiências de aprendizagem através de atividades de enriquecimento curricular; e a categoria adesão a projetos nacionais e/ou internacionais refere-se à expansão da rede de parcerias das diferentes escolas que se encontram diretamente relacionadas com a implementação de diversos projetos em âmbito nacional e internacional.

\section{APRESENTAÇÃO DOS RESULTADOS}

Como se referiu, dos 104 relatórios analisados, 52 correspondem ao $1^{\mathrm{o}}$ ciclo de AEE (2006-2011) e 52 ao 2o ciclo (2011-2014). Estes relatórios distribuem-se equitativamente pelos agrupamentos de escolas que, neste $2{ }^{\circ}$ ciclo de AEE, subiram as classificações, desceram ou as mantiveram.

Foram identificadas 427 referências ou unidades de sentido - frases e/ou parágrafos - relativas a parcerias escola-comunidade. Dessas referências, a maior porcentagem foi encontrada em relatórios do 1o ciclo de avaliação (271 referências) e em escolas com classificações mais baixas 
(236 referências). A análise permitiu ainda identificar: áreas de parcerias privilegiadas na relação da escola com a comunidade; efeitos dessas parcerias; e as áreas de parcerias associadas aos efeitos identificados.

\section{Áreas das Parcerias}

Centrando-nos na primeira dimensão-áreas das parcerias - constata-se, numa leitura global, que nas parcerias estabelecidas entre as escolas e as comunidades é dada maior ênfase à categoria relacionada com a formação/desenvolvimento profissional. Há referências a esta categoria em 54 relatórios, seguida da categoria relacionada com área social, onde foram identificadas referências em 40 relatórios. As categorias relacionadas com parcerias no âmbito das áreas da saúde e da intervenção familiar são expressas em 38 e em 25 relatórios, respectivamente.

Relacionando a percentagem de referências às diferentes áreas das parcerias com as classificações atribuídas aos agrupamentos de escolas (classificações mais altas e classificações mais baixas) constata-se a distribuição representada no Gráfico 1.

Como se constata pelo Gráfico 1, todas as categorias são mais referenciadas nos relatórios de escolas com classificações mais altas, à exceção das áreas de apoio psicológico, saúde e equipamento e serviços educativos. Sendo as duas últimas áreas determinantes na melhoria dos resultados dos alunos, tal pode significar que estes sejam domínios em que as escolas com classificações mais baixas estejam investindo mais.

Relativamente à área social, constata-se que ela mostra igual representatividade (50\%) para os dois tipos de classificação de escolas, e que é seguida pelas áreas intervenção familiar e saúde. As parcerias de âmbito social estão associadas a ações de voluntariado e de solidariedade, bem como a atividades de educação para a cidadania, entre outras. Os excertos transcritos de dois relatórios são exemplo disso:

São também oferecidas atividades e projetos de âmbito local, nacional e internacional promotores do desenvolvimento cívico e da educação para a cidadania (IGEC, Relatórios do 2º Ciclo de AEE, 2011-2014-classificações mais baixas).

Estão implementadas práticas de voluntariado e de solidariedade desenvolvidas individualmente pela Escola, das quais se destacam: o projeto "Voluntariado na Escola: queres que te ajude a estudar?" - que revela bons resultados na integração dos alunos mais novos -, e outras 
Carlinda Leite, Preciosa Fernandes, Ana Mouraz e Marta Sampaio

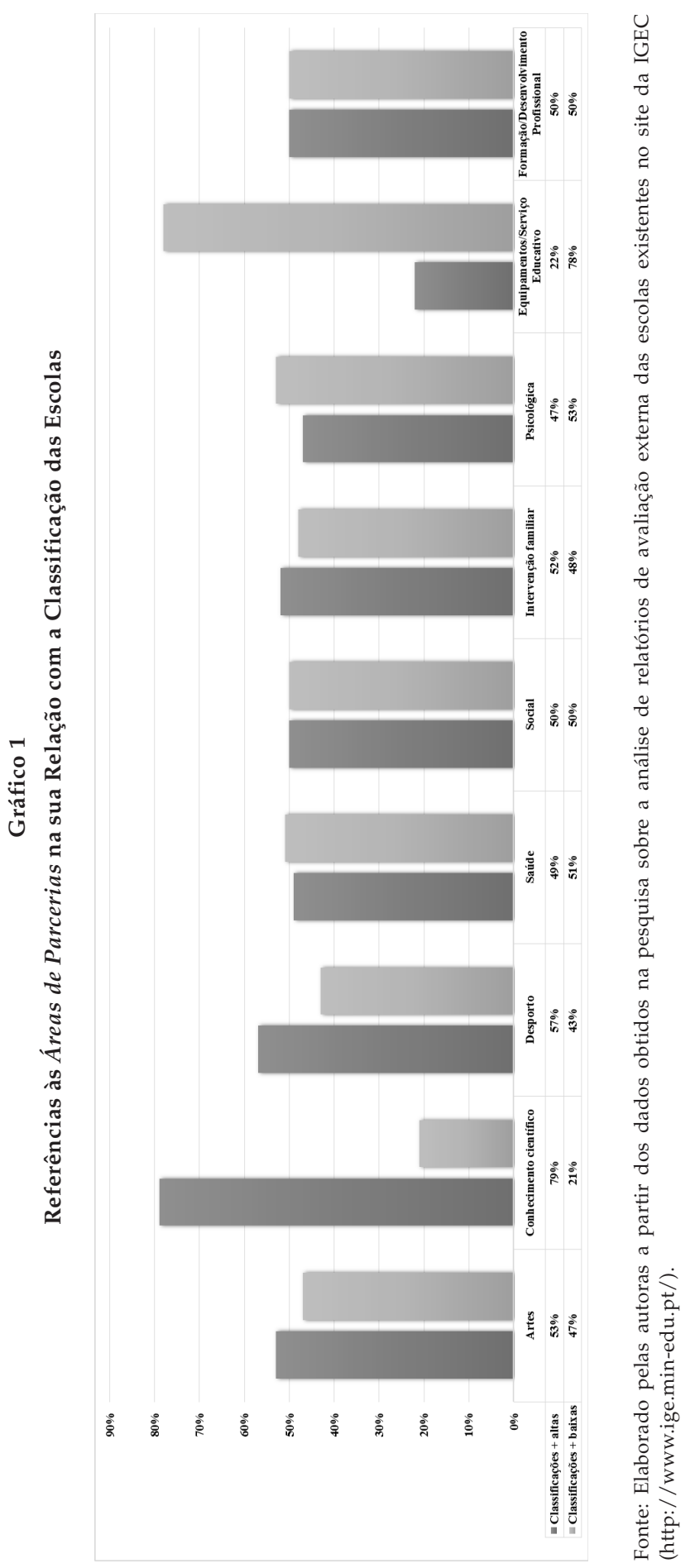

836 DADOS - Revista de Ciências Sociais, Rio de Janeiro, vol. 58, nº 3, 2015 
(p. ex., "Ser Cidadão, Aprender a ser com os Outros", "Especial Príncipes do Nada"), em articulação com instituições de solidariedade social, particularmente na recolha e distribuição de bens e na implementação de projetos (IGEC, Relatórios do 2ํCiclo de AEE, 2011-2014 - classificações mais baixas).

Quanto ao apoio psicológico, as parcerias dizem respeito sobretudo à procura de serviços de psicologia em instituições da comunidade no sentido de poder proporcionar aos alunos melhor acompanhamento psíquico. Por outro lado, da análise dos relatórios constata-se que, em algumas escolas, os serviços de psicologia e de orientação escolar são procurados para um trabalho conjunto com as famílias. A intenção é proporcionar o apoio possível aos alunos, no que se refere, principalmente, a questões relacionadas com a orientação vocacional e o prosseguimento dos estudos. Estes elementos podem ser ilustrados através dos seguintes excertos:

O trabalho conjunto e articulado dos psicólogos da Comissão de Proteção de Crianças e Jovens e do Programa Escolhas tem promovido a participação dos pais na resolução dos problemas causados por alunos com dificuldades de integração (IGEC, Relatórios do 2o Ciclo de AEE, 2011-2014 - classificações mais baixas).

O agrupamento trabalha em articulação com as juntas de freguesia de $X$ e, com particular incidência, com a de $\mathrm{X}$-designadamente no recurso a técnicos de serviço social e psicólogos (IGEC, Relatórios do 1ํ Ciclo de AEE, 2006-2011 - classificações mais baixas).

Em relação ao apoio às famílias, as referências identificadas nos dois tipos de relatório, isto é, nos com classificações mais altas e naqueles com classificações mais baixas, são muito próximas. A análise realizada permitiu inferir que o principal objetivo das parcerias que a este nível são estabelecidas (com a Comissão de Proteção de Crianças e Jovens, por exemplo) é prestar apoio às famílias. Diz respeito especificamente a casos de risco de abandono escolar ou de dificuldades de integração dos alunos ou, ainda, a casos de famílias com crianças portadoras de necessidades educativas especiais. Também é manifesto o interesse em fomentar a participação dos pais/encarregados de educação nas várias atividades desenvolvidas, para que estes acompanhem ativamente o cotidiano escolar e atribuam um maior valor às aprendizagens realizadas pelos discentes. São expressos argumentos como:

São muito valorizadas a formação realizada junto dos pais, as atividades que envolvem a comunidade e a circulação de pessoas e bens no ter- 
ritório devido à existência desta instituição educativa (IGEC, Relatórios do 2ํㅡㄹ Ciclo de AEE, 2011-2014 - classificações mais altas).

Foram implementadas várias parcerias para o desenvolvimento de projetos de inovação e também para possibilitar o alargamento das aprendizagens, assim como para apoiar as famílias dos alunos (IGEC, Relatórios do 1ํCiclo de AEE, 2006-2011 - classificações mais baixas).

No que respeita à área da saúde, constata-se que a maior parte das escolas, na rede de parcerias que institui, tem protocolos estabelecidos com Centros de Saúde e algumas delas tendem a desenvolver e/ou promover atividades ou projetos de Educação para a Saúde, tal como evidencia o seguinte excerto:

Assumem ainda valor estratégico as parcerias estabelecidas com o Centro de Saúde local e com as entidades cooptadas no conselho geral (farmácia, Bombeiros e Clube Desportivo X) pelas experiências de aprendizagem proporcionadas aos alunos no âmbito da saúde, da formação profissional e voluntariado e do desporto (IGEC, Relatórios do 2o Ciclo de AEE, 2011-2014 - classificações mais baixas).

Em relação aos equipamentos/serviços educativos, as referências identificadas e a análise detalhada dos relatórios indicam que as parcerias estabelecidas visam o apetrechamento de salas de aulas com quadros interativos; disponibilização de transportes; organização de atividades de ocupação dos tempos livres; formação de pessoal do bar e cantina e cartões eletrônicos para segurança dos alunos. Este tipo de parceria tem ainda como objetivo manter e ampliar os recursos existentes nas escolas, no sentido de proporcionar condições adequadas à vivência escolar dos alunos e aos processos de ensino e de aprendizagem. Ilustra estes argumentos o seguinte excerto:

(...) as candidaturas a projetos pedagógicos têm permitido a obtenção de algumas receitas, as quais se destinam à aquisição de equipamento de suporte às actividades de ensino-aprendizagem. Na educação pré-escolar e no 1ํo ciclo, o Agrupamento tem vindo a beneficiar da colaboração activa das autarquias locais, designadamente da Câmara Municipal de $\mathrm{X}$ e das Juntas de Freguesia, não só no que concerne à manutenção das condições físicas e materiais, mas também no assegurar das refeições destinadas aos alunos ou nos transportes necessários para esse efeito (IGEC, Relatórios do 1ํCiclo de AEE, 2006-2011 - classificações mais altas). 
No que se refere à categoria formação/desenvolvimento profissional, o Gráfico 1 mostra tratar-se de uma área igualmente presente, tanto em escolas que têm classificações mais altas como nas que têm classificações mais baixas. É de salientar, da análise dos vários relatórios, que as práticas mais comuns de atualização profissional se focam, entre outros, nos seguintes aspectos: atividades de enriquecimento curricular; realização de estágios em contexto de trabalho; formação linguística para alunos de outras nacionalidades; experiências formativas relacionadas com o objetivo de diminuir o abandono escolar; procura e oferta de estágios para alunos com necessidades educativas especiais; formação ao nível do desenvolvimento cívico e de educação para a cidadania; incentivo e valorização dos saberes práticos e profissionais e desenvolvimento da componente vocacional nos alunos.

O Gráfico 1 evidencia ainda que a área conhecimento científico é mais referenciada em relatórios de escolas com classificações mais altas. Este fato pode expressar um maior investimento e valorização pela escola no estabelecimento de parcerias que possibilitem o contato dos alunos com novas experiências, bem como a abertura da escola a iniciativas de aprofundamento dos conhecimentos. A atenção que é dada a esta área pelas escolas tem também subjacente uma diretiva política que aponta neste sentido. Efetivamente, o governo português define como meio para a melhoria da aprendizagem dos alunos o recurso ao ensino experimental das ciências em todo o ensino fundamental (Ministério da Educação, 2007). Esta situação, que é tida em consideração na avaliação das escolas, leva-as a estabelecer parcerias com instituições da comunidade de modo a proporcionar aos alunos o desenvolvimento de competências de caráter científico e laboratorial. A este propósito é referido num dos relatórios analisados que:

(há uma) rentabilização das parcerias estabelecidas com o meio, nomeadamente com a Escola Superior de Educação de " $X$ "3 no sentido da implementação de projetos no âmbito do ensino experimental das ciências, sobretudo em contexto de sala de aula (IGEC, Relatórios do 1으clo de AEE, 2006-2011 - classificações mais altas).

No que diz respeito à componente artística, pode observar-se no Gráfico 1 que, quer nos relatórios das escolas avaliadas com classificações mais altas, quer nos de escolas com classificações mais baixas, foram identificadas referências num número muito próximo. Também em relação a este aspecto é referido num relatório de uma escola avaliada no 1ํo ciclo: 
O mesmo se passa com a dimensão artística, estimulada não apenas pelos cursos existentes, mas também pela parceria com a academia de música local, através da participação em concertos Promenade, pelas exposições periódicas levadas a cabo pelos grupos de recrutamento na Escola e nos edifícios oficiais da cidade, pela participação em atividades de cinema de animação, Cinanima, e pelo envolvimento em projetos como o Aprender a ver a cidade, os espaços e as obras (IGEC, Relatórios do 1ํㅡㄹ Ciclo de AEE, 2006-2011 - classificações mais altas).

Este dado é, mais uma vez, convergente com diretivas políticas como, por exemplo, o programa de Atividades de Enriquecimento Curricular (Despacho 16.795/2005, de 23 de agosto). Instituído em 2005/2006, este programa teve como objetivo propiciar o desenvolvimento de atividades, de caráter opcional, no domínio das artes, do desporto e do ensino de outras linguas estrangeiras, o que conferiu mais visibilidade à componente artística no currículo escolar. Desde então, as escolas estão legitimadas para proporcionar aos alunos experiências mais abrangentes, que não se restrinjam apenas ao currículo formal. Para isso, tem sido dinamizada a participação em projetos culturais, em atividades relacionadas com música e expressão dramática, que favorecem o desenvolvimento de competências sociais e artísticas.

No que respeita a atividades desportivas, e como alguns agrupamentos de escolas não têm as condições necessárias para o desenvolvimento destas atividades, são usados, muitas vezes, equipamentos da comunidade local para suprir esta necessidade. Grande parte da relação entre a escola e a comunidade foca-se na dimensão desportiva e no apoio ao desporto escolar, de que são exemplos: oferta de transportes por parte das autarquias; aluguel de pavilhões desportivos; cessão dos pavilhões das escolas às autarquias e vice-versa. É também notório o esforço de algumas escolas/agrupamentos em participar de projetos relacionados com a Educação para a Saúde. Estas evidências estão muito presentes nos relatórios analisados e são aqui ilustradas através do seguinte excerto:

Existem parcerias com várias instituições que visam responder às necessidades destes alunos em vários domínios, tais como natação, equitação, terapia da fala e ocupacional, psicologia, transição para a vida pós-escolar e cuidados de saúde específicos (IGEC, Relatórios do 2 Ciclo de AEE, 2011-2014 - classificações mais altas). 
A análise permitiu ainda verificar que algumas escolas/agrupamentos estabelecem, também por determinação legal, parcerias com empresas do meio, como, por exemplo, instituições de ensino superior da região e o Instituto do Emprego e Formação Profissional (IEFP). Este tipo de parceria tem como intenção integrar alguns alunos no mercado de trabalho, tal como é expresso no seguinte excerto:

As parcerias existentes com as empresas da região decorrem da determinação legal para o funcionamento dos cursos de índole essencialmente prática, quer sejam dos CEF quer sejam dos cursos tecnológicos. Dada a diversidade dos cursos lecionados na Escola, tem sido fundamental a articulação com o Núcleo Empresarial de X e outras entidades, tais como Instituições Particulares de Solidariedade Social (IPSS), para a integração dos formandos no mundo do trabalho (IGEC, Relatórios do 1을 Ciclo de AEE, 2006-2011 - classificações mais baixas).

Em síntese, a análise permitiu apurar que as relações entre a escola e a comunidade existem tanto nos casos com classificações mais altas como nas que obtêm classificações mais baixas. Como o Gráfico 1 revela, há um equilíbrio no número de referências às várias categorias, sendo a diferença maior nas áreas de conhecimento científico e de equipamentos/serviços educativos.

\section{Efeitos das Parcerias}

A análise realizada permitiu identificar referências a três tipos de efeitos das parcerias: (1) adesão a projetos nacionais e/ou internacionais (referências identificadas em 86 relatórios); (2) inovação curricular (referências identificadas em 58 relatórios); (3) alargamento da oferta formativa (referências identificadas em 46 relatórios) (ver Gráfico 2).

As referências que permitiram a construção do Gráfico 2 traduzem a intenção de criar novas dinâmicas escolares através da adesão a projetos relacionados com o currículo escolar e que promovam a qualidade da prestação do serviço educativo e a melhoria dos resultados. Estes dados refletem, por sua vez, uma atenção cada vez maior por parte das escolas e dos professores em desenvolver ações que liguem a escola à comunidade, promovendo dinâmicas educacionais que vão para além das fronteiras organizacionais (Nóvoa, 2009). Concomitantemente apontam para perspectivas de trabalho em equipe, quer entre professores, quer entre professores e alunos, e para um trabalho coletivo de 


\section{Gráfico 2}

Referências a Efeitos das Parcerias nos Relatórios

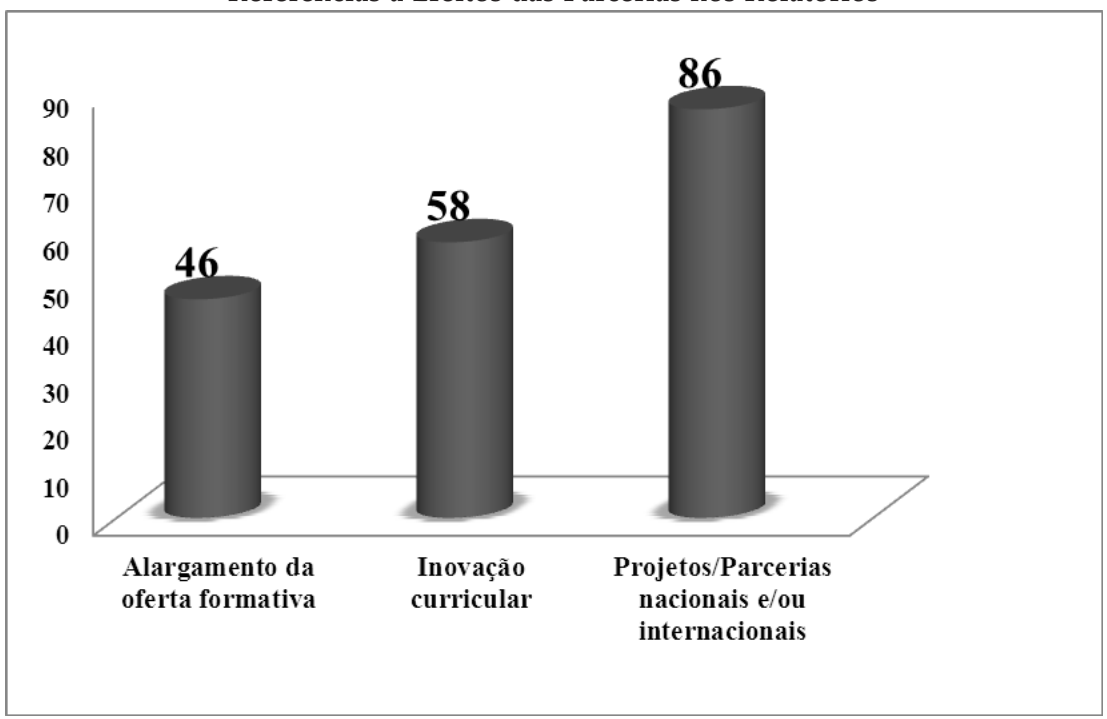

Fonte: Elaborado pelas autoras a partir dos dados obtidos na pesquisa sobre a análise de relatórios de avaliação externa das escolas disponíveis no site da IGEC (http://www.ige.min-edu.pt/).

toda a escola, em estreita cooperação com o restante da comunidade (Bolívar, 2007).

A leitura detalhada dos relatórios corrobora a visão representada no Gráfico 2, permitindo perceber que muitas das parcerias estabelecidas têm como principal efeito promover projetos que ampliem o currículo formal e proporcionem a docentes e discentes a oportunidade de entrar em contato com novas experiências e aprendizagens. O seguinte excerto exemplifica este tipo de efeito:

Nos últimos anos foram lançados vários projetos, tendo como protagonistas várias estruturas educativas, contribuindo, deste modo, para a qualidade da oferta curricular disponibilizada pela Escola. A Escola desenvolve também um conjunto alargado de projetos, procurando, com isso, facultar aos alunos novas oportunidades de aprendizagem dentro e fora da sala de aula (IGEC, Relatórios do 1o Ciclo de AEE, 2006-2011 - classificações mais altas).

Este registro legitima ainda que a criação de redes de parcerias e o estabelecimento de novos protocolos parecem representar um caminho para uma maior diversificação das experiências de aprendizagem. Ao mesmo tempo, representam uma forma de potenciar a formação inte- 
gral dos alunos e obter efeitos ao nível do combate ao abandono escolar e à indisciplina. A este propósito são referidas nos relatórios as seguintes ideias:

A adesão a projetos locais e nacionais, a implementação de algumas medidas inovadoras (planos Bem Estar e Controlo da Disciplina) e a dinâmica de transversalidade dos projetos produzem um efeito positivo na criação de um bom ambiente de trabalho e na diversificação de experiências e oportunidades de aprendizagem para os discentes (IGEC, Relatórios do 2을 Ciclo de AEE, 2011-2014 - classificações mais altas).

A abertura e a ligação à comunidade através do estabelecimento de conexões com diversas entidades externas, (...) tem favorecido o trabalho em rede para o desenvolvimento de iniciativas conjuntas e a utilização dos recursos (IGEC, Relatórios do 20 Ciclo de AEE, 2011-2014 - classificações mais altas).

Como se depreende dos enunciados dos relatórios, a adesão a projetos é reconhecida como um efeito central das parcerias para dar resposta a problemas concretos e melhorar a formação dos alunos. A análise mostra ainda que as instituições locais reconhecem a importância da escola / agrupamento para o desenvolvimento cultural e econômico das populações que serve.

A adesão a projectos e a atividades inovadoras, conjugada com o estabelecimento de uma rede de parcerias, tem tido impacto apreciável na melhoria das condições de funcionamento dos jardins-de-infância e das escolas, bem como no enriquecimento e no reforço das aprendizagens escolares (IGEC, Relatórios do 1ํㅡㄹ Ciclo de AEE, 2006-2011 - classificações mais baixas).

Ao nível do desenvolvimento e inovação foram identificados aspectos relacionados com: a participação em várias iniciativas de âmbito nacional e internacional; a rentabilização das parcerias já existentes; a implementação de medidas de integração social; dinâmicas de cooperação com entidades locais; a atitude de inovação e criatividade evidenciada por alguns agrupamentos; e a adesão a parcerias com um caráter estratégico no desenvolvimento da ação educativa.

Refira-se ainda que os vários projetos e parcerias são desenvolvidos a diferentes níveis e têm como objetivo responder a diversas necessidades. Este fato, em alguns casos, possibilita às escolas assumirem-se como uma importante e prestigiada instituição da região em que se en- 
contram inseridas. É também considerado que o número e a qualidade das parcerias estabelecidas permitem criar uma forte ligação com a comunidade e um bom relacionamento com as autarquias. Deste bom relacionamento resultam projetos que envolvem agentes da comunidade local, o que contribui para a promoção do interesse e visibilidade da vida escolar. Neste mesmo sentido, algumas escolas mostram como intenção fazer com que os próprios encarregados de educação comecem a valorizar mais as aprendizagens. São exemplos desta situação os excertos:

O Agrupamento tem uma dinâmica de articulação com a comunidade local, integrando alunos estagiários, promovendo intercâmbios e geminação com outras escolas de países da União Europeia, fomentando protocolos com entidades empregadores, para assegurar a formação em contexto de trabalho dos CEF (cursos de Educação e Formação), e participando em projetos nacionais e internacionais (IGEC, Relatórios do 1ํ Ciclo de AEE, 2006-2011 - classificações mais altas).

É desenvolvido um conjunto variado de iniciativas através de clubes temáticos, projetos de intercâmbio escolar internacional, viagens de estudo, comemoração de efemérides (em particular no aniversário da Escola), participação na revista Ipsis Verbis, palestras, workshops, exposições, concursos e eventos culturais, artísticos e desportivos, que visam propiciar aos alunos novos saberes e experiências de aprendizagem (IGEC, Relatórios do 1ํㅡㄹ Ciclo de AEE, 2006-2011 - classificações mais altas).

\section{Relação entre Áreas de Parcerias e seus Efeitos}

Analisando as referências identificadas relativamente às diversas áreas de parcerias (num total de 278), é possível relacioná-las com os três efeitos anteriormente explicitados. Essa relação é ilustrada na Tabela 1.

Uma análise da Tabela 1 permite constatar que as áreas artes e serviços de psicologia são as que apresentam um maior número de referências e estão relacionadas com a adesão a projetos nacionais e internacionais. Por sua vez, as áreas do desporto e conhecimento científico são as que revelam maior número de referências associadas a efeitos ao nível da inovação curricular. Igualmente as áreas da formação/desenvolvimento profissional e do desporto são as que evidenciam um maior número de referências relacionadas com o efeito de alargamento da oferta formativa. Em síntese, pode-se considerar que as parcerias entre a escola e a comuni- 
Tabela 1

Relação entre Áreas de Parcerias e seus Efeitos

\begin{tabular}{l|c|c|c}
\hline \multirow{2}{*}{ Área das Parcerias } & \multicolumn{3}{|c}{ Efeitos } \\
\cline { 2 - 4 } & $\begin{array}{c}\text { Alargamento da } \\
\text { Oferta Formativa }\end{array}$ & $\begin{array}{c}\text { Inovação } \\
\text { Curricular }\end{array}$ & $\begin{array}{c}\text { Adesão a Projetos } \\
\text { Nacionais e/ou } \\
\text { Internacionais }\end{array}$ \\
\hline Artes & $13 \%$ & $0 \%$ & $87 \%$ \\
Científico & $21 \%$ & $14 \%$ & $65 \%$ \\
Desporto & $43 \%$ & $21 \%$ & $36 \%$ \\
Equipamentos/serviços & $17 \%$ & $0 \%$ & $83 \%$ \\
$\quad$ educativos & $22 \%$ & $4 \%$ & $74 \%$ \\
Intervenção familiar & $47 \%$ & $9 \%$ & $44 \%$ \\
Formação/desenvolvimento & $19 \%$ & $2 \%$ & $79 \%$ \\
$\quad$ profissional & $0 \%$ & $0 \%$ & $100 \%$ \\
Saúde & $13 \%$ & $10 \%$ & $77 \%$ \\
Serviços de psicologia & & & \\
Social & & & \\
\hline
\end{tabular}

Fonte: Elaborada pelas autoras a partir dos dados obtidos na pesquisa sobre a análise de relatórios de avaliação externa das escolas disponíveis no site da IGEC (http:/ / www.ige.min-edu.pt/).

dade são reconhecidas por favorecerem dinâmicas enriquecedoras da formação dos alunos, contribuindo, igualmente, para a valorização da escola na comunidade. Da mesma forma, a escola é reconhecida como um polo de desenvolvimento local.

\section{CONSIDERAÇÕES FINAIS}

Recorreu-se, nesse artigo, a uma análise de relatórios da avaliação externa a que são sujeitas as escolas públicas do ensino fundamental em Portugal, no pressuposto de que estes traduzem a forma como elas se relacionam com o meio em que estão inseridas. Através desta análise, identificaram-se áreas de parcerias estabelecidas pelas escolas e por elas privilegiadas na relação com as comunidades, assim como os efeitos produzidos. Os conceitos de territorialização da ação educativa, de descentralização e de uma escola aberta ao meio constituíram referenciais teóricos de análise para a elaboração do estudo.

Respondendo às questões que orientaram a pesquisa, a análise dos dados recolhidos permite reconhecer que as escolas valorizam as parcerias, apesar de serem as que têm classificações mais baixas as que lhe dão maior importância. Uma interpretação possível para esta situação 
prende-se ao conceito de subsidiariedade com que as escolas perspectivam o seu papel educativo. Isto é, infere-se que são as escolas em contextos mais difíceis que sentem mais necessidade de aprofundar relações com a comunidade de modo a responder aos problemas com os quais convivem. Essa maior importância verifica-se também em três áreas (saúde, apoio social e apoio psicológico) que se interligam e contribuem para fortalecer a relação da escola com o local em que está inserida. Parece poder inferir-se que o estabelecimento de parcerias tem como intenção contribuir para uma educação de melhor qualidade (Estaço, 2001). Nesta leitura, as parcerias representam também mais-valias para aproximar as escolas das famílias (Van Zanten, 2010) e para o desenvolvimento de processos curriculares mais contextualizados (Fernandes et al., 2013) e mais justos (Connell, 1997; Apple, Beane, 2000; Santomé, 2013). Esta é também a razão que justifica que a territorialização seja compreendida como uma prática de suporte às dificuldades sentidas pela instituição escolar. Na linha desta interpretação, a territorialização curricular torna-se mais necessária nos contextos social e economicamente mais desfavorecidos, situação que é corroborada pelo modo como a AEE enuncia o entendimento da importância das parcerias do ponto de vista das instituições locais.

Também se constatou que nas escolas com classificações mais baixas as parcerias foram estabelecidas em maior número nas áreas do apoio psicológico e dos equipamentos/serviços educativos, quando comparadas com as escolas melhor classificadas. Estas constatações levam a crer tratar-se de escolas que precisam recorrer ao local para colmatar dificuldades que as outras muitas vezes não têm. Nesta sequência, a melhoria da instituição escolar e da educação que nela ocorre está intrinsecamente associada à forma como os agentes escolares implementam as suas práticas de partilha e de construção coletiva. Inclusivamente, esta pode ser favorecida pela relação com as famílias e com outros elementos da comunidade educativa, numa perspectiva de ação comunitária (Santos, 1994).

As escolas com classificações mais altas valorizaram, mais do que aquelas que tiveram classificações mais baixas, a área do conhecimento científico para estabelecerem parcerias. Esta situação é reflexo da diretiva política que aponta para a importância do ensino experimental das ciências no ensino fundamental (Ministério da Educação, 2007), mas também da disponibilidade para centrarem-se neste desafio. Por outro lado, e se associarmos a valorização que estas escolas atribuem ao des- 
porto como área de parceria, tal fenômeno pode ser explicado por uma concepção alargada do sentido de escolaridade. Por sua vez, esta ideia é compatível com a existência de um conhecimento poderoso, isto é, um conhecimento mais especializado, teórico, que vai além do conhecimento disciplinar (Young, 2010). Por último, e no que diz respeito ao envolvimento das famílias, a análise permite inferir que as escolas com classificações mais altas recorrem a este tipo de relação como suporte para alcançar elevadas taxas de sucesso escolar, tendência que está de acordo com as investigações de A. Van Zanten (2010).

As parcerias estabelecidas para promover e coadjuvar a formação/desenvolvimento profissional dos professores não diferenciam as escolas avaliadas, pois este foi um aspecto valorizado igualmente pelos dois grupos. Este elemento pode ser simultaneamente significativo da importância que os professores atribuem ao investimento na profissão, e ao reconhecimento de que o seu desenvolvimento profissional poderá ser melhor garantido se estabelecerem redes com outros agentes educativos locais. Poder-se-á também entender esta evidência como resultante de uma compreensão da profissão desenvolvida em contextos de interações e enquanto uma ação coletiva (Tardif e Lessard, 2005). Esta visão parece ter subjacente o princípio de que a melhoria da educação se constrói no interior da escola, com os profissionais que nela trabalham e que, coletivamente, se comprometem com a mudança (Bolívar, 2007; Leite e Fernandes, 2010). Similarmente pode também construirse no seu exterior através da relação estabelecida com os parceiros locais, no quadro dos princípios de uma educação como responsabilidade social (Leite, 2003).

Centrando agora a atenção sobre os efeitos gerados pelas parcerias, e retomando os dados apresentados anteriormente constatou-se que as escolas com classificações mais altas aderem mais a projetos internacionais que as escolas menos bem classificadas. Estas últimas tendem a fazer parcerias com instituições mais próximas, mais locais. Uma explicação plausível reside na importância atribuída ao contato dos alunos com situações do meio mais próximo ou mais afastado do seu cotidiano. Enquanto as primeiras veem a sua missão ampliada em nível internacional, de modo a preparar os alunos para uma cidadania universal, as segundas estão focalizadas na resolução dos problemas que o cotidiano as obriga a enfrentar (Raveaud e Van Zanten, 2007).

Em síntese, e de acordo com a análise de dados realizada, foi possível perceber que grande parte dos agrupamentos de escolas apresenta um 
elevado número de parcerias e de protocolos com instituições locais e que estas são reconhecidas por favorecerem dinâmicas enriquecedoras da aprendizagem e da formação global dos alunos. Por outro lado, permite também saber que a procura e o estabelecimento de parcerias se desenvolvem num duplo sentido. De um lado, o sentido da integração da comunidade na vida da escola e, de outro, o sentido da escola responder às necessidades da comunidade. Infere-se, então, que as parcerias estabelecidas não são encaradas apenas como simples recurso para minimizar algumas das necessidades mais instrumentais do projeto educativo de cada escola/agrupamento.

Constatou-se ainda que, de um modo geral, essas parcerias concorrem para a valorização da escola na comunidade, sendo reconhecido o seu contributo para o desenvolvimento local. Ao mesmo tempo, constituem uma condição importante na corresponsabilização coletiva pela educação e funcionamento das escolas e para a promoção da inovação curricular. Todavia, as escolhas dos parceiros não são independentes dos problemas que as escolas enfrentam e dos objetivos que perseguem, constatando-se nessa diferença marcas de alguma influência dos territórios sociais que as escolas servem.

(Recebido para publicação em março de 2014)

(Reapresentado em dezembro de 2014) (Aprovado para publicação em junho 2015) 


\section{NOTAS}

1. Em Portugal, desde 1998, as escolas, por determinação legal (Decreto-Lei no 115-A/98), têm sido agrupadas de modo a associarem num mesmo agrupamento de uma determinada zona geográfica a educação pré-escolar, o ensino fundamental e o ensino médio.

2. Inspeção Geral da Educação e Ciência - Quadro de referência para a avaliação externa das escolas 2011-2012. Disponível em http://www.min-edu-pt. Acesso em $14 / 1 / 2014$.

3. Disponível em http://repositorio-aberto.up.pt/bitstream/10216/64409/2/80013. pdf. Acesso em 20/1/2014.

4. Apesar de os relatórios de AEE disponibilizados pela IGEC estarem disponíveis para consulta pública, todos os nomes de escolas/agrupamentos, cidades e freguesias estão designados por " $\mathrm{X}$ ". 


\section{REFERÊNCIAS BIBLIOGRÁFICAS}

AFONSO, Almerindo Janela. (2009), "Políticas Avaliativas e Accountability em Educação: Subsídios para um Debate Ibero-americano". Sísifo: Revista de Ciências da Educação, no 9, pp. 57-70.

AFONSO, Natércio; COSTA, Estela. (2011), “A Avaliação Externa das Escolas: Um Instrumento de Regulação baseado no Conhecimento", in J. Barroso; N. Afonso (orgs.), Políticas Educativas: Mobilização de Conhecimentos e Modos de Regulação. Gaia, Fundação Manuel Leão, pp. 155-189.

ALVES, Fátima. (2010), “Escolhas Familiares, Estratificação Educacional e Desempenho Escolar: Quais as Relações?". DADOS - Revista de Ciências Sociais, vol. 53, no 2, pp. $447-468$

ANDRADE, Eduarda. (2003), "A Construção de um CFAE: Lógicas de Ação e Práticas de Territoralização Educativa”. Educação, Sociedade \& Culturas, no 20, pp. 103-124.

APPLE, Michael; BEANE, James. (2000), Escolas Democráticas. Porto, Porto Editora.

BARBIERI, Helena. (2003), “Os Teip, o Projeto Educativo e a Emergência de ‘Perfis de Território'”. Educação, Sociedade \& Culturas, no 20, pp. 43-75.

BARDIN, Laurence. (2011), Análise de Conteúdo. São Paulo, Edições 70.

BATISTA, Susana. (2012), A Relação Escola-comunidade: Políticas e Práticas. Lisboa, Projeto ESCXEL (Rede de Escolas de Excelência).

BEANE, James. (2000), “O que é um Currículo Coerente?”, in J. A. Pacheco (org.), Políticas de Integração Curricular. Porto, Porto Editora, pp. 39-58.

BOLÍVAR, Antonio. (2007), Como Melhorar as Escolas: Estratégias e Dinâmicas de Melhorias das Práticas Educativas. Porto, Edições ASA.

BURGOS, Marcelo. (2012), “Escola Pública e Segmentos Populares em um Contexto de Construção Institucional da Democracia". DADOS - Revista de Ciências Sociais, vol. 55, no 4, pp. 1015-1054.

CAVALIERE, Ana Maria. (2002), “Quantidade e Racionalidade do Tempo de Escola: Debates no Brasil e no Mundo". TEIAS, vol. 6, no 3, pp. 1-15.

. (2007), “Tempo de Escola e Qualidade na Educação Pública”. Educação E Sociedade, vol. 100, no 28, pp. 1015-1035.

CHAUVEAU, Gérard. (1982), "As Zonas de Educação Prioritárias: Lutar contra as Desigualdades Escolares? As Novas Experiências Educativas em França". Análise Psicológica, vol. 4, no 11, pp. 507-618.

CLARK, Bill. (2000), The Quality Initiative in Scottish Schools. Working together to achieve Excellence. Disponível em http://www.oei.es/calidad2/paper.PDF. Acesso em $5 / 3 / 2013$.

CLÍMACO, Maria do Carmo. (2005), Avaliação de Sistemas em Educação. Lisboa, Universidade Aberta.

CONNELL, Robert. (1997), Escuelas y Justicia Social. Madrid, Edições Morata. 
CORREIA, José Alberto. (2004), Políticas e Lógicas da Territorialização: Contributos para a Produção Emancipatória do Local. Arbores IIl. Almada, ICE \& Sebastian, pp. 17-29.

;CARAMELO, João. (2008), “Políticas e Figuras do Local: Contributos para a Construção de um Cosmopolitismo Comunitário". Ideação - Revista do Centro de Educaçãoe Letras da Unioeste, vol. 10, no 2, pp. 59-72.

DALE, Roger. (1989), The State and Education Policy. Milton Keynes, Open University Press.

DAVIES, Philip; NEWCOMER, Kathryn; SOYDAN, Haluk. (2007), "Government as Structural Context for Evaluation", in I. F. Shaw; J. C. Greene; M. M. Mark (eds.), Handbook of Evaluation: Policies, Programs and Practices. London, Sage Publications, pp. 163-183.

DELGADO, Nelson; LEITE, Sérgio. (2011), “Políticas de Desenvolvimento Territorial no Meio Rural Brasileiro: Novas Institucionalidades e Protagonismo dos Atores". DADOS - Revista de Ciências Sociais, vol. 54, no 2, pp. 431-473.

DIAS, Maria Natália. (2003), Políticas Educativas e Dispositivos de Territorialização: Da Escola Aberta à Comunidade à Escola em Parceria. Dissertação de mestrado. Faculdade de Psicologia e Ciências da Educação, Universidade do Porto, Porto.

DOLL JR., William. (2004), “Currículo e Controlo". Revista de Estudos Curriculares, vol. 2, no 1, pp. 7-41.

ESTAÇO, Isabel M. Ramos. (2001), A Escola, as Parcerias e a Mudança: Teoria e Prática. Contributos de um Estudo Empírico. Lisboa, Instituto de Inovação Educacional.

FAURE, Edgar. (1981), Aprender a Ser. Lisboa, Bertrand.

FERNANDES, Preciosa et al. (2013), "Curricular Contextualization: Tracking the Meanings of a Concept". The Asia-Pacific Education Researcher, vol. 22, no 4, pp. $417-425$.

FERREIRA, Fernando Ilídio. (2005), O Local em Educação: Animação, Gestão e Parceria. Lisboa, Fundação Calouste Gulbenkian.

. (2012), “O Tempo das Redes: Redes que Aprisionam e Redes que Libertam”, in C. Cebolo; J. Pereira; M. Lopes (coords.), Animação Sociocultural: Intervenção e Educação Comunitária: Democracia, Cidadania e Participação. Chaves, Intervenção, pp. 355-368.

FORMOSINHO, João. (2005), “A Construção da Autonomia das Escolas: Lógicas Territoriais e Lógicas Afinitárias”, in J. Formosinho et al. (orgs.), Administração da Educação: Lógicas Burocráticas e Lógicas de Mediação. Porto, Edições ASA, pp. 307-319.

FULLAN, Michael; RINCON-GALLARDO, Santiago; HARGREAVES, Andy. (2015), "Professional Capital as Accountability". Education Policy Analysis Archives, vol. 23, no 15, pp. 1-22.

IGEC (Inspeção Geral da Educação e da Ciência). (2011), Proposta para um Novo Ciclo de Avaliação Externa de Escolas: Relatório final. Lisboa, Ministério da Educação. Disponível em http://www.ige.min-edu.pt/upload\%5CRelatorios/AEE2_GT_ 2011_RELATORIO_FINAL.pdf. Acessado em 27/3/2013. 


\section{Carlinda Leite, Preciosa Fernandes, Ana Mouraz e Marta Sampaio}

. Relatórios do 1ํCiclo de AEE (2006-2011). Ministério da Educação. Disponível em http: / / www.ige.min-edu.pt/content_01.asp?BtreeID=03/01\&treeID=03/01/03 / 00\&auxID= Acessado em 27/3/2013.

. Relatórios do 2o Ciclo de AEE (2011- 2014). Ministério da Educação. Disponível em http://www.ige.min-edu.pt/content_01.asp?BtreeID=03/01\&treeID=03/01/ 03/00\&auxID= Acessado em 27/3/2013.

KRIPPENDORF, Klaus. (2003), Content Analysis: An Introduction to its Methodology. Beverly Hills, Sage.

LEITE, Carlinda. (2003), “Projeto Educativo de Escola, Projeto Curricular de Escola, Projeto Curricular de Turma: O que Têm de Comum? O que os Distingue". Revista Forma, no 5, pp. 11-18.

. (2005), “A Territorialização das Políticas e das Práticas Educativas", in C. Leite (org.), Mudanças Curriculares em Portugal: Transição para o Século XXI. Porto, Porto Editora, pp. 15-32.

LEITE, Carlinda; FERNANDES, Preciosa. (2010), "A Autoavaliação das Escolas no Sistema Educativo Português: Do Discurso Legal aos Sentidos dos Processos em Curso". Elo, no 17, pp. 59-71.

LEITE, Carlinda; FERNANDES, Preciosa; SILVA, Sofia Marques da. (2013), “O Lugar da Educação para a Cidadania no Sistema Educativo Português: Perspetivas de Docentes de uma Escola TEIP". Educação, vol. 36, no 1, pp. 35-43.

LEITE, Carlinda; PACHECO, José Augusto. (2010), Para uma Clarificação de Conceitos que Atravessam "a Prestação do Serviço Educativo", do Processo de Avaliação Externa de Escolas. Lisboa, Inspeção Geral da Educação.

LEITE, Carlinda; RODRIGUES, Lurdes; FERNANDES, Preciosa. (2006), “A Autoavaliação das Escolas e as Melhorias da Qualidade da Educação: Um Olhar Reflexivo a partir de uma Situação". Revista de Estudos Curriculares, vol. 4, no 1, p. 21-45.

MINISTÉRIO DA EDUCAÇÃO. (2007), Educação e Formação em Portugal. Ministério da Educação. Disponível em: http://www.dgeec.mec.pt/np4/97/\%7B\$clientServletPath\%7D/?newsId=147\&fileName=educacao_formacao_portugal.pdf. Acessado em $2 / 12 / 2014$.

NÓVOA, António. (2009), “Para uma Formação de Professores Construída dentro da Profissão". Revista Educación, no 350. Disponível em http://www.revistaeducacion.mec.es/re350/re350_09por.pdf. Acessado em 29/6/2013.

OECD (Organization for Economic Co-operation and Development). (2012), “OECD Reviews of Evaluation and Assessment in Education: Portugal 2012". Disponível em http:/ /dx.doi.org/10.1787/9789264117020-en. Acessado em 14/1/2014.

RAVEAUD, Maroussia; VAN ZANTEN, Agnès. (2007), "Choosing the Local School? Middle Class Parents' Values and Social and Ethnic Mix in London and Paris". Journal of Education Policy, vol. 22, no 1, pp. 107-124.

ROCHEX, Jean-Yves. (2011), “As Três Idades das Políticas de Educação Prioritária: Uma Convergência Europeia”. Educação e Pesquisa, vol. 37, no 4, pp. 871-882. 
RODRIGUES, Fernanda; STOER, Stephen. (1994), "Ação Local e Cidadania", in Associação Portuguesa de Sociologia: Atas do Encontro Dinâmicas Culturais, Cidadania e Desenvolvimento Local. Lisboa, APS, pp. 175-188.

SANTIAGO, Paulo et al. (2012), OECD Reviews of Evaluation and Assessment in Education: Portugal 2012. Lisboa, OECD Publishing.

SANTOMÉ, Jurjo Torres. (2013), Currículo Escolar e Justiça Social: O Cavalo de Tróia da Educação. Porto Alegre, Penso.

SANTOS, Boaventura de Sousa. (1994), Pela Mão de Alice: O Social e o Político na pós-Modernidade. Porto, Afrontamento.

SARMENTO, Manuel Jacinto. (2002), “Infância, Exclusão Social e Educação como Utopia Realizável”. Educação, Sociedade \& Culturas, no 17, pp. 13-32.

TARDIF, Maurice; LESSARD, Claude. (2005), O Trabalho Docente. Elementos para uma Teoria da Docência como Profissão de Interações Humanas. Petrópolis, Vozes.

TURA, Maria de Lourdes; SILVA, Sofia M. (2010), “Etnografia da Prática Pedagógica em Contextos de Multiculturalidade: O Caso de uma Escola no Rio de Janeiro e de uma Escola no Porto", in M. L. Rangel; C. Leite (orgs.), Questões de Currículo e Trabalho Docente. Rio de Janeiro, Quartet, pp. 71-105.

VAN ZANTEN, Agnès. (2010), “Choix de l'École et Inégalités Scolaires: Le Rôle des Ressources Culturelles et Économiques des Parents". Agora Débats/Jeunesses, vol. 3, no 56, pp. 35-47.

VELOSO, Luísa; ABRANTES, Pedro; CRAVEIRO, Daniela. (2011), “A Avaliação Externa de Escolas como Processo Social”. Educação, Sociedade E Culturas, no 33, pp. 69-88.

VILAR CABALLO, Maria Belén. (2001), A Cidade Educadora de Organização e Intervenção Municipal. Lisboa, Piaget.

YOUNG, Michael. (2010), Conhecimento e Currículo: Do Socioconstrutivismo ao Realismo Social na Sociologia da Educação. Porto, Porto Editora. 


\title{
RESUMO
}

Parcerias entre a Escola e a Comunidade em Portugal: Uma Análise a partir da Avaliação Externa das Escolas

O artigo examina as relações de parceria entre escola e comunidade em Portugal, analisando-as a partir da avaliação externa a que as escolas são sujeitas. Os objetivos principais são conhecer a importância dada ao estabelecimento de relações de parceria entre as escolas e a comunidade, caracterizar as áreas de parcerias privilegiadas e avaliar os efeitos gerados. Para isso foram analisados 52 relatórios de avaliação externa de escolas, que representam 20,8\% da totalidade dos agrupamentos de escolas existentes em 2012 e 2013 no Norte e no Centro de Portugal, e $60 \%$ das escolas avaliadas nesses anos. Os dados permitem concluir, entre outros aspectos, que grande parte das escolas / agrupamentos apresenta um elevado número de parcerias com instituições locais e que estas são muito reconhecidas por favorecerem dinâmicas enriquecedoras de aprendizagem e de formação global dos alunos.

Palavras-chave: parcerias; desenvolvimento local; territorialização da educação; formação escolar; avaliação de escolas

\author{
ABSTRACT \\ Partnerships between School and Community in Portugal: An Analysis \\ based on External Evaluation of Schools
}

The article examines the partnership between school and community in Portugal, analyzing them based on the external evaluations to which schools are subjected. The main goals are to understand the importance attributed to the establishment of partnerships between schools and communities outline the areas of privileged partnerships and evaluate the generated effects. To this effect 52 external evaluation reports were analyzed, representing $20.8 \%$ of total school districts as of 2012 and 2013 in the North and Center of Portugal and $60 \%$ of schools evaluated in these years. The data leads to the conclusion that, among other aspects, most schools/school groups present a high number of partnerships with local institutions and that they can certainly provide enriching dynamics in learning and overall upbringing of students.

Keywords: partnerships; local development; territorialization of education; schooling; school evaluation 


\section{RÉSUMÉ}

Partenariats entre École et Communauté au Portugal: Une Analyse à partir de l'Évaluation Externe des Écoles

Le présent article analyse les relations de partenariat entre école et communauté au Portugal à partir de l'évaluation externe à laquelle sont soumis les établissements scolaires. Les principaux objectifs consistent à rendre compte de l'importance accordée aux relations de partenariat entre les écoles et la communauté, à identifier les domaines privilégiés de ces associations et d'en évaluer les effets. À cette fin, nous avons analysé cinquante-deux rapports d'évaluation externe d'écoles, ce qui correspond à 20,8\% de l'ensemble des groupes scolaires existants en 2012 et 2013 dans le Nord et le Centre du Portugal, et à $60 \%$ des écoles évaluées lors de ces deux années. Les données nous ont permis de conclure, entre autres aspects, qu'une grande partie des écoles/groupes scolaires jouit d'un nombre important de partenariats avec des institutions locales, et que cela favorise aux yeux de tous des dynamiques enrichissantes d'apprentissage et de formation globale des élèves.

Mots-clés: partenariats; développement local; territorialisation de l'éducation; formation scolaire; évaluation des écoles

\section{RESUMEN \\ Colaboraciones entre la Escuela y la Comunidad en Portugal: Un Análisis desde la Evaluación Externa de las Escuelas}

El artículo examina las relaciones de colaboración entre escuela y comunidad en Portugal teniendo en cuenta la evaluación externa a la cual los centros educativos están sujetos. Los objetivos principales son conocer la importancia dada al establecimiento de relaciones entre las escuelas y la comunidad, caracterizar las áreas de asociación privilegiadas y evaluar los efectos generados. Se analizaron para ello 52 informes de evaluación externa de las escuelas, lo que representa el 20,8\% del total de agrupaciones escolares existentes en 2012 y 2013 en el Norte y en el Centro de Portugal, bien como el 60\% de las escuelas evaluadas en esos años. Los datos permiten concluir que gran parte de las escuelas/agrupaciones escolares presenta un elevado número de colaboraciones con instituciones locales y que estas son muy reconocidas por fortalecer dinámicas innovadoras de aprendizaje y de formación global de los estudiantes.

Palabras clave: asociaciones; desarrollo local; territorialización de la educación; formación escolar; evaluación de las escuelas 